\title{
ATMOSPHERIC MODELS FOR MARS AEROCAPTURE
}

\author{
C. G. Justus ${ }^{(1)}$, Aleta Duvall ${ }^{(1)}$, Vernon W. Keller ${ }^{(2)}$ \\ ${ }^{(1)}$ Morgan Research Corporation, 4811-A Bradford Drive, Huntsville, AL 35805 - \\ 1948 (USA), Jere.Justus@msfc.nasa.gov, Aleta.Duvall@msfc.nasa.gov \\ ${ }^{(2)}$ NASA Marshall Space Flight Center, EV13, Marshall Space Flight Center, AL \\ 35812 (USA), Vernon.Keller@nasa.gov
}

\begin{abstract}
Mars Global Reference Atmospheric Model (Mars-GRAM) is a widely-used engineeringlevel Mars atmospheric model. Applications include systems design, performance analysis, and operations planning for aerobraking, entry descent and landing, and aerocapture. Typical Mars aerocapture periapsis altitudes (for systems with rigidaeroshell heat shields) are about $50 \mathrm{~km}$. This altitude is above the $0-40 \mathrm{~km}$ height range covered by Mars Global Surveyor Thermal Emission Spectrometer (TES) nadir observations. Recently, TES limb sounding data have been made available, spanning more than two Mars years (more than 200,000 data profiles) with altitude coverage up to about $60 \mathrm{~km}$, well within the height range of interest for aerocapture. Results are presented comparing Mars-GRAM atmospheric density with densities from TES nadir and limb sounding observations. A new Mars-GRAM feature is described which allows individual TES nadir or limb profiles to be extracted from the large TES databases, and to be used as an optional replacement for standard Mars-GRAM background (climatology) conditions. For Monte-Carlo applications such as aerocapture guidance and control studies, Mars-GRAM perturbations are available using these TES profile background conditions.
\end{abstract}

\section{INTRODUCTION}

Mars Global Reference Atmospheric Model (Mars-GRAM) is an engineering-level atmospheric model widely used for diverse mission applications (Justus et al., 2003, 2004a-e; Duvall et al., 2005). From $0 \mathrm{~km}$ to $80 \mathrm{~km}$ altitude, Mars-GRAM is based on NASA Ames Mars General Circulation Model (MGCM) (Haberle et al., 1993), while above $80 \mathrm{~km}$ it is based on Mars Thermospheric General Circulation Model (MTGCM) (Bougher et al., 1990). Mars-GRAM and MGCM use surface topography from Mars Global Surveyor Mars Orbiter Laser Altimeter (MOLA) (Smith and Zuber, 1998), with altitudes referenced to the MOLA constant potential surface (areoid).

Mars-GRAM 2001, the previous version of Mars-GRAM, has been validated (Justus et al., 2004a,d) against data from Radio Science (RS) observations (Hinson, et al., 1999), and from Thermal Emission Spectrometer (TES) nadir profiles (Smith et al., 2001). A just-released version of Mars-GRAM, Mars-GRAM 2005, is described here and is validated against RS data, nadir TES data, and TES data from Mars limb soundings (Conrath et al., 1999). While both the RS and TES nadir data extend up to an altitude of about $40 \mathrm{~km}$, TES limb data reach altitudes of about $60 \mathrm{~km}$ or slightly higher. Results from comparison of Mars-GRAM with TES limb data are particularly relevant for 
aerocapture at Mars, since aerocapture periapsis altitude would typically be in the range of about 40-60 km, i.e. above the height range covered by RS or TES nadir data.

\section{NEW MARS-GRAM FEATURES}

Two new features of Mars-GRAM 2005 that are of importance for aerocapture are:

(1) Option to use input data sets from MGCM and MTGCM model runs that were designed to closely simulate the conditions observed during the first two years of TES observations at Mars (TES Year $1=$ April 1999 through January 2001; TES Year $2=$ February 2001 through December 2002).

(2) Option to read and use any "auxiliary profile" of temperature and density versus altitude.

In exercising the auxiliary profile Mars-GRAM option, the alternate data (i.e. values from the auxiliary profile) totally replace data from the original MGCM/MTGCM databases. One example of an auxiliary profile would be data from RS or TES (nadir or limb) observations at a particular location and time.

\section{VALIDATION OF MARS-GRAM 2005}

For Mars-GRAM 2001 validation studies (Justus et al., 2004 a,d), 2,480 RS profiles were compared with Mars-GRAM results for the same location and time as each RS profile. Mars-GRAM 2005 climatology has been compared with over 12,000 RS profiles, approximately 5 times as many as for the 2001 comparison. The new, larger RS database provides more complete seasonal (Ls) coverage, over a wide range of latitudes, than represented in the earlier validation comparisons. Figure 1 presents results of average Mars-GRAM minus RS atmospheric density as a function of height and latitude, with all seasons (Ls values) combined. At almost all heights and latitudes, mean Mars-GRAM density differs by less than $10 \%$ from mean RS density. These results are slightly better than for the comparison of RS data with Mars-GRAM 2001, where a zone of slightly greater than $10 \%$ differences was seen at heights above about $32 \mathrm{~km}$ and latitudes poleward of about $50 \mathrm{~N}$.

Comparisons of Mars-GRAM 2005 climatology with TES limb data (Conrath et al., 1999) have also been conducted. Figure 2 compares atmospheric density profiles from Mars-GRAM 2005 and TES limb data at representative Phoenix landing conditions (Ls = 78 degrees, latitude $=67.5 \mathrm{~N}$, longitude $=223.1 \mathrm{E}$, for limb data from TES Year 1). The TES limb data profile in Figure 2 is an average of 17 individual limb profiles that are near this location and time. The average TES limb profile, formatted for use as an "auxiliary profile" in Mars-GRAM 2005, is also given in Table 1. Zero wind values in Table 1 indicate that no wind observations are available, so original MGCM wind values are assumed. Figure 2 shows good agreement between Mars-GRAM 2005 and TES limb 


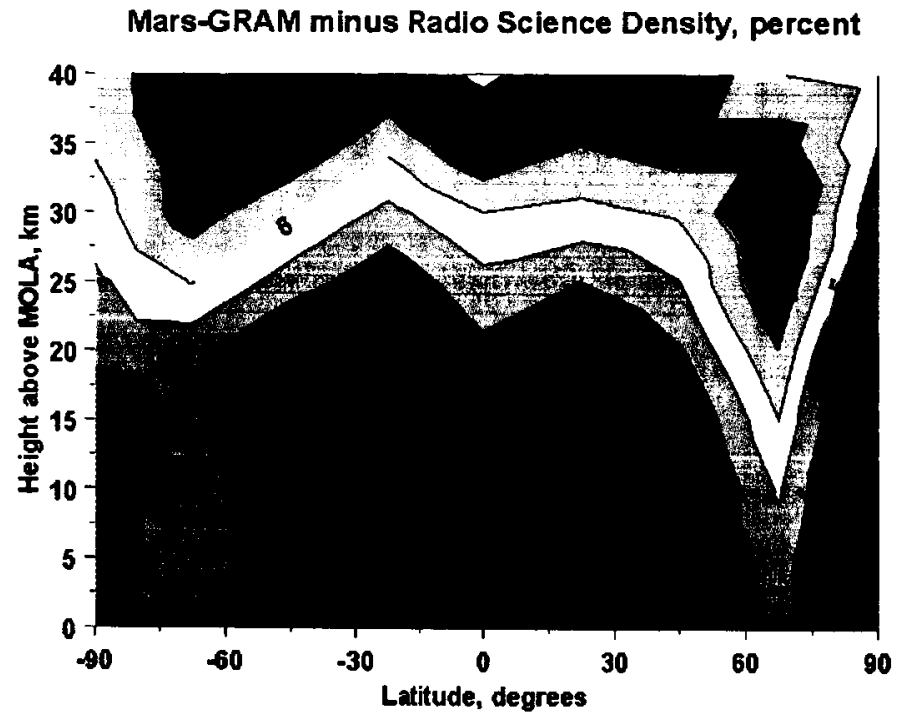

Figure 1 - Average Mars-GRAM minus RS atmospheric density as a function of height and latitude

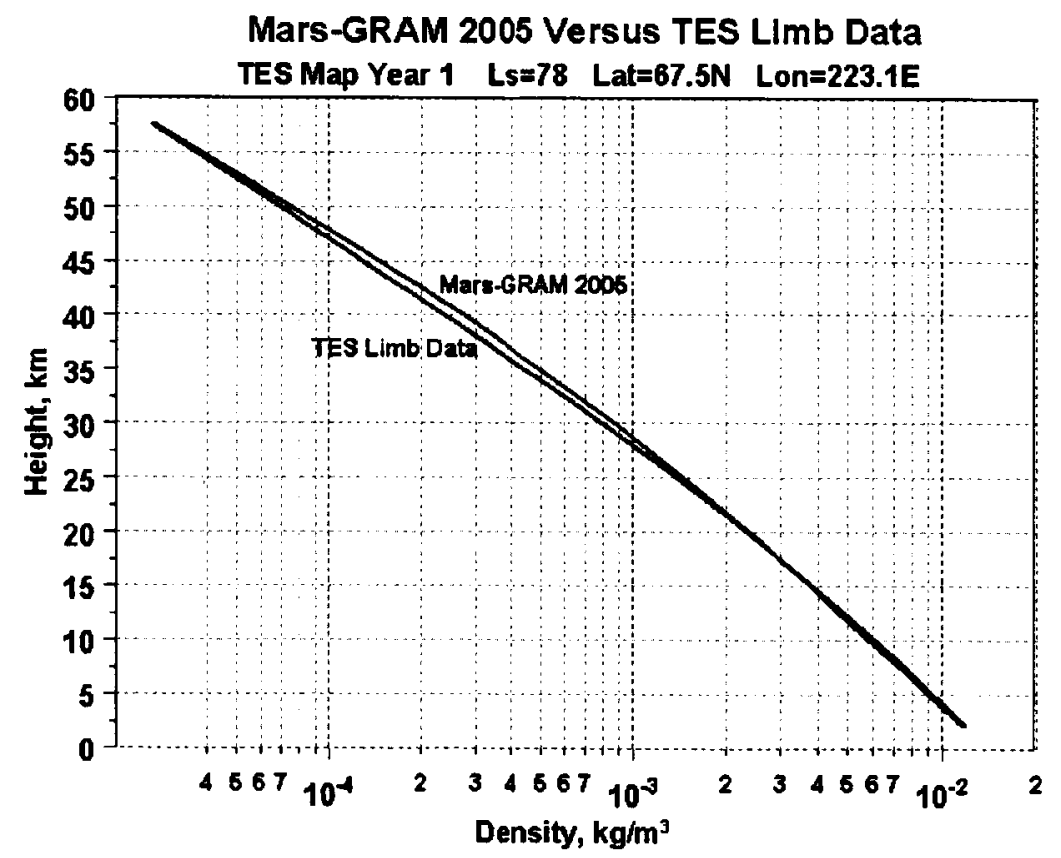

Figure 2 - Density profiles from Mars-GRAM 2005 and TES limb data at representative Phoenix landing conditions 
Table 1 - Sample Mars-GRAM 2005 Auxiliary Profile (Average of 17 TES Limb Profiles at Phoenix Landing Conditions)

$\begin{array}{rccccccr}\text { Height } & \text { Lat } & \text { LonE } & \text { TempK } & \text { PresNm2 } & \text { Denskgm3 } & \text { Uwind } & \text { Vwind } \\ 2.172 & 67.50 & 223.10 & 209.39 & 4.751 \mathrm{E}+02 & 1.187 \mathrm{E}-02 & .00 & .00 \\ 4.825 & 67.50 & 223.10 & 203.59 & 3.700 \mathrm{E}+02 & 9.509 \mathrm{E}-03 & .00 & .00 \\ 7.408 & 67.50 & 223.10 & 197.79 & 2.881 \mathrm{E}+02 & 7.622 \mathrm{E}-03 & .00 & .00 \\ 9.921 & 67.50 & 223.10 & 192.08 & 2.244 \mathrm{E}+02 & 6.113 \mathrm{E}-03 & .00 & .00 \\ 12.365 & 67.50 & 223.10 & 186.63 & 1.748 \mathrm{E}+02 & 4.900 \mathrm{E}-03 & .00 & .00 \\ 14.744 & 67.50 & 223.10 & 181.46 & 1.361 \mathrm{E}+02 & 3.925 \mathrm{E}-03 & .00 & .00 \\ 17.062 & 67.50 & 223.10 & 176.77 & 1.060 \mathrm{E}+02 & 3.138 \mathrm{E}-03 & .00 & .00 \\ 19.326 & 67.50 & 223.10 & 172.53 & 8.255 \mathrm{E}+01 & 2.504 \mathrm{E}-03 & .00 & .00 \\ 21.540 & 67.50 & 223.10 & 168.64 & 6.429 \mathrm{E}+01 & 1.995 \mathrm{E}-03 & .00 & .00 \\ 23.709 & 67.50 & 223.10 & 165.22 & 5.007 \mathrm{E}+01 & 1.586 \mathrm{E}-03 & .00 & .00 \\ 25.838 & 67.50 & 223.10 & 162.06 & 3.900 \mathrm{E}+01 & 1.259 \mathrm{E}-03 & .00 & .00 \\ 27.931 & 67.50 & 223.10 & 159.20 & 3.037 \mathrm{E}+01 & 9.982 \mathrm{E}-04 & .00 & .00 \\ 29.992 & 67.50 & 223.10 & 156.83 & 2.365 \mathrm{E}+01 & 7.891 \mathrm{E}-04 & .00 & .00 \\ 32.029 & 67.50 & 223.10 & 155.03 & 1.842 \mathrm{E}+01 & 6.218 \mathrm{E}-04 & .00 & .00 \\ 34.048 & 67.50 & 223.10 & 153.86 & 1.435 \mathrm{E}+01 & 4.881 \mathrm{E}-04 & .00 & .00 \\ 36.057 & 67.50 & 223.10 & 153.15 & 1.117 \mathrm{E}+01 & 3.822 \mathrm{E}-04 & .00 & .00 \\ 38.061 & 67.50 & 223.10 & 152.50 & 8.700 \mathrm{E}+00 & 2.991 \mathrm{E}-04 & .00 & .00 \\ 40.051 & 67.50 & 223.10 & 151.68 & 6.780 \mathrm{E}+00 & 2.344 \mathrm{E}-04 & .00 & .00 \\ 42.039 & 67.50 & 223.10 & 150.77 & 5.280 \mathrm{E}+00 & 1.837 \mathrm{E}-04 & .00 & .00 \\ 44.019 & 67.50 & 223.10 & 149.83 & 4.110 \mathrm{E}+00 & 1.439 \mathrm{E}-04 & .00 & .00 \\ 45.987 & 67.50 & 223.10 & 148.78 & 3.200 \mathrm{E}+00 & 1.129 \mathrm{E}-04 & .00 & .00 \\ 47.948 & 67.50 & 223.10 & 147.71 & 2.490 \mathrm{E}+00 & 8.851 \mathrm{E}-05 & .00 & .00 \\ 49.888 & 67.50 & 223.10 & 146.72 & 1.940 \mathrm{E}+00 & 6.946 \mathrm{E}-05 & .00 & .00 \\ 51.825 & 67.50 & 223.10 & 145.76 & 1.510 \mathrm{E}+00 & 5.446 \mathrm{E}-05 & .00 & .00 \\ 53.720 & 67.50 & 223.10 & 144.75 & 1.180 \mathrm{E}+00 & 4.289 \mathrm{E}-05 & .00 & .00 \\ 55.646 & 67.50 & 223.10 & 143.68 & 9.170 \mathrm{E}-01 & 3.360 \mathrm{E}-05 & .00 & .00 \\ 57.546 & 67.50 & 223.10 & 142.68 & 7.140 \mathrm{E}-01 & 2.636 \mathrm{E}-05 & .00 & .00\end{array}$

densities for heights up to about $30 \mathrm{~km}$, and above about $50 \mathrm{~km}$. Mars-GRAM 2005 density becomes about $15 \%$ higher than TES limb density near $40 \mathrm{~km}$ altitude.

In contrast to the high latitude case shown in Figure 2, Figure 3 compares Mars-GRAM 2005 density at equatorial conditions (for $L s=120$ ) with both TES limb data and TES nadir data. TES limb and nadir data agree quite well with each other, over the full height range for which nadir data are available. Figure 3 shows that Mars-GRAM 2005 density agrees well with both types of TES data, up to a height of about $30 \mathrm{~km}$. However, MarsGRAM 2005 densities begin to deviate (on the low side) from TES limb data above about $30 \mathrm{~km}$, with Mars-GRAM densities being about $40 \%$ lower than TES limb data between about $45 \mathrm{~km}$ and $55 \mathrm{~km}$.

Figure 4 shows results from Mars-GRAM versus TES limb data density comparisons, averaged over all seasons (all Ls values), all latitudes, and both TES years 1 and 2. This figure shows average Mars-GRAM minus TES density (as percent of TES density) versus height and latitude. Figure 4 shows that results from Figures 2 and 3 are not atypical. At high northern latitudes, Figure 4 indicates that Mars-GRAM agrees closely with TES limb data, with Mars-GRAM being about $10 \%$ to $15 \%$ larger than TES near $40 \mathrm{~km}$ altitude. This behavior is similar to that shown in Figure 2. In contrast, Figure 4 shows 
TES and MarS-GRAM Denslty

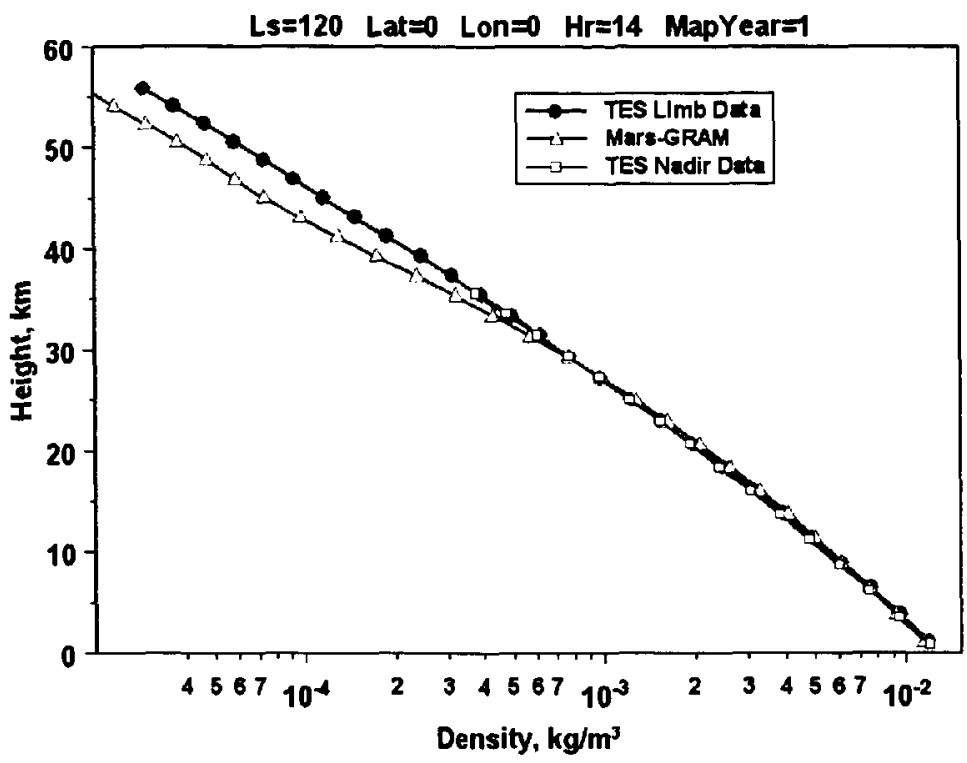

Figure 3 - Density profiles from Mars-GRAM 2005, TES nadir data, and TES limb data, at equator, for Ls $=120$.

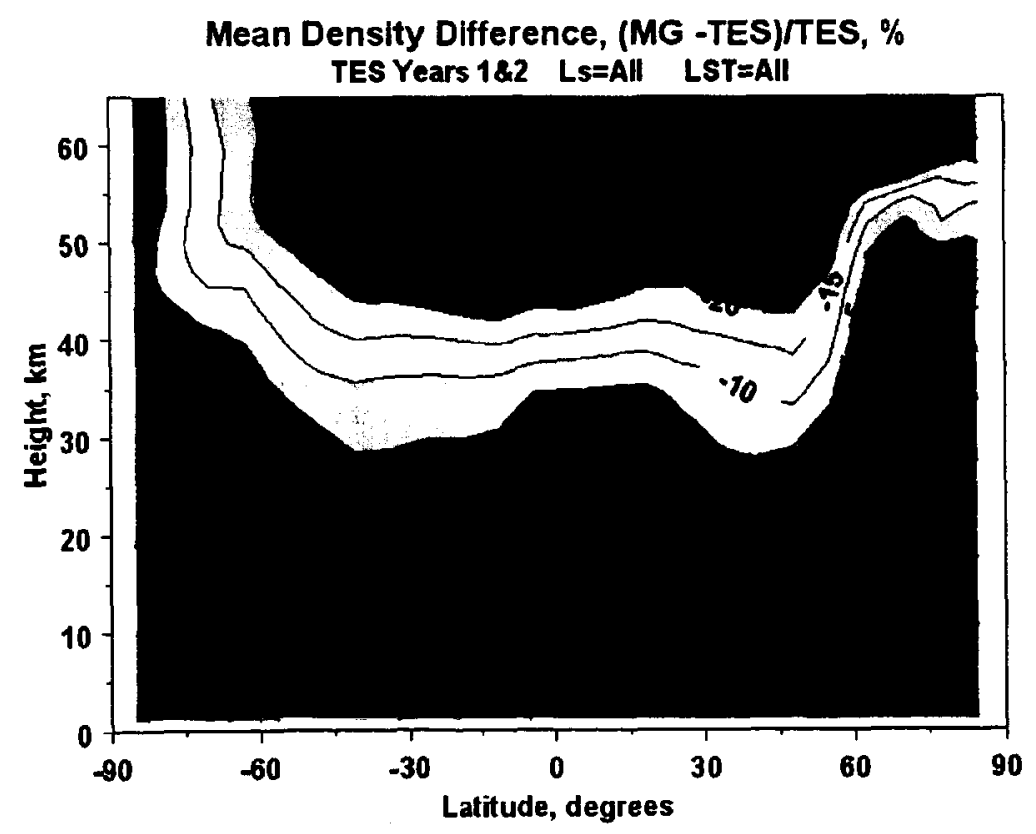

Figure 4 - Mean density difference, Mars-GRAM 2005 minus TES limb data, versus height and latitude 


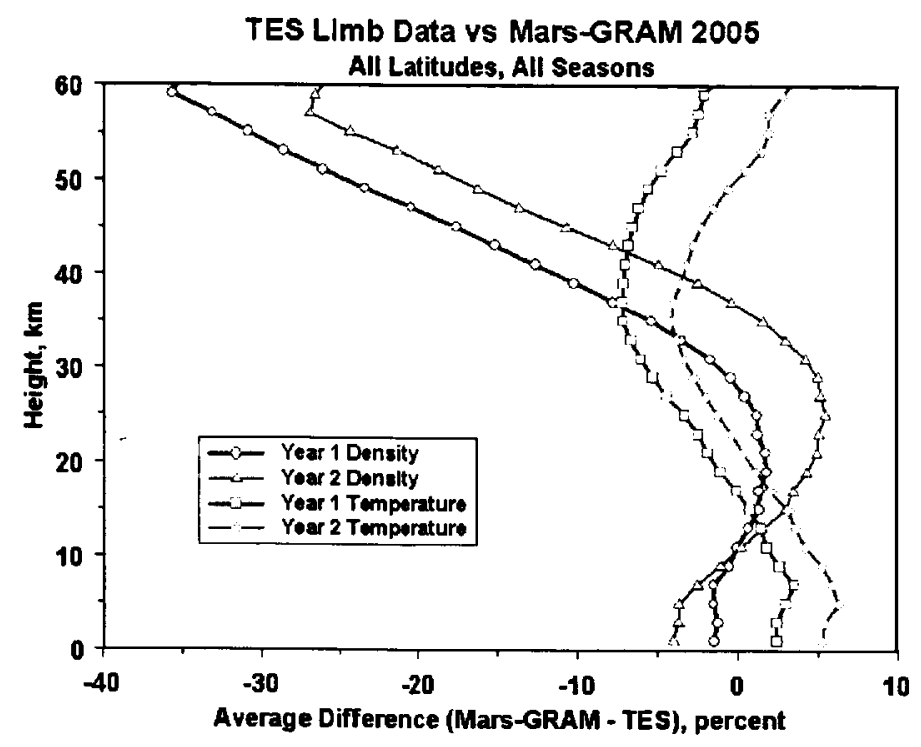

Figure 5 - Comparison of Mars-GRAM 2005 density and temperature with TES limb data, for all seasons and latitudes

that, over a broad range of low and middle latitudes, Mars-GRAM densities are significantly lower than TES limb densities for heights of about $40 \mathrm{~km}$ and higher, analogous to Figure 3.

Figure 5 shows mean altitude profiles of Mars-GRAM 2005 versus TES limb density and temperature, averaged over all latitudes and seasons (all Ls values), separately for TES Years 1 and 2. In this figure, differences in both mean density and temperature are given in percent. A large, global-scale dust storm occurred during TES Year 2 (Smith, 2004). Note, however, that average Mars-GRAM versus TES comparisons for density and temperature are actually slightly better for TES Year 2 than for TES Year 1. This result would seem to indicate that Mars-GRAM (and MGCM on which it is based) represents dust effects at least as well during dust storm conditions as during non-storm conditions. Figure 5 confirms that the tendency of Mars-GRAM to underestimate density at high altitudes (especially at low-to-middle latitudes) is a feature of both TES Years 1 and 2.

Figure 5 indicates that the tendency of Mars-GRAM to underestimate density at high altitudes (40 to $60 \mathrm{~km}$ ) results from a "cold bias" in Mars-GRAM temperatures over this upper altitude region. If Mars-GRAM temperatures are colder than observed, over an extended altitude region, then hydrostatics forces Mars-GRAM density to become lower than observed, by a exponentially-increasing amount, as the depth of the cold bias layer increases. A "rule of thumb" approximation to estimate effects of such bias is that if a temperature bias $= \pm x$ (in percent) persists over a layer of depth $=n$ scale heights, then the density deviation at the top of the layer will be $\pm x \times n$ (in percent), assuming density deviation starts at zero at the bottom of the layer. For TES Year-1 data in Figure 5, we have $\mathrm{x}$ averaging about $-5 \%$ over the layer from about $15 \mathrm{~km}$ to about $55 \mathrm{~km}$ altitude (roughly 5 scale heights). The rule of thumb thus gives a density deviation $=-5 \% \times 5$ 
scale heights $=-25 \%$ at the top of this layer, is good agreement with observed density deviations at the 55-km layer top.

Preliminary studies by Murphy (2005) using various vertical dust profiles suggest that MGCM's tendency to yield a cold bias results from too little dust at upper altitudes in the normal MGCM vertical dust distribution. Mars-GRAM 2005, which is based upon MGCM output, reflects this cold bias. For a given total dust loading (dust optical depth), increasing the relative amount of dust at higher altitudes in MGCM would produce additional heating of the upper altitude layers, thereby reducing or removing the cold bias and the resulting Mars-GRAM tendency toward low densities compared to observations. Until updated MGCM data are available for incorporation in Mars-GRAM, it may be advisable for aerocapture studies to use auxiliary profiles from TES limb data as MarsGRAM input conditions.

\section{CONCLUSIONS}

The new Mars-GRAM option to use "auxiliary profiles" derived from TES limb data will be especially useful for aerocapture analyses. For aerocapture maneuvers with periapsis at low-to-middle latitudes, TES limb density data are typically larger than Mars-GRAM density by as much as $40 \%$ at periapsis altitudes (40 to $60 \mathrm{~km})$. At high northern and southern latitudes, agreement is better between Mars-GRAM and TES limb densities. However, at high northern latitudes, such as planned for Phoenix entry and landing, Mars-GRAM overestimates density compared to TES limb data by about $10-15 \%$ in the 30 to $45-\mathrm{km}$ height range.

\section{ACKNOWLEDGMENTS}

The authors gratefully acknowledge support from the NASA Office of Space Sciences Mars Data Analysis Program (MDAP) and the MSFC In-Space Propulsion Technology Office. Particular thanks are extended to Jim Murphy, New Mexico State University, for providing MGCM output and comparative data. User feedback and suggestions from the following individuals are also greatly appreciated: Lee Bryant, Tim Crull, and Wyatt Johnson of NASA Jet Propulsion Laboratory; John Aguirre of Vigyan, Inc.; and Richard Powell of NASA Langley Research Center.

\section{REFERENCES}

Bougher, S. W., et al., "The Mars Thermosphere: 2. General Circulation with Coupled Dynamics and Composition", Journal of Geophysical Research, 95(B9), 14,811-14,827, 1990.

Conrath, B. J., Pearl, J. C., Smith, M. D., and Christensen, P. R., "Mars Global Surveyor TES Results: Atmospheric Thermal Structure Retrieved from Limb Measurements", American Astronomical Society, Division of Planetary Sciences Meeting \#31, \#49.08, September, 1999. 
Duvall, A. L., Justus, C. G., and Keller, V. W., "Global Reference Atmospheric Model (GRAM) Series for Aeroassist Applications", AIAA-2005-1239, 43rd AIAA Aerospace Sciences Meeting and Exhibit, Reno, Nevada, January 10-13, 2005.

Haberle, R. M., et al., "Mars Atmospheric Dynamics as Simulated by the NASA Ames General Circulation Model 1. The Zonal-Mean Circulation", Journal of Geophysical Research, 98(E2), 3093-3123, 1993.

Hinson, D. P., Simpson, R. A., Twicken, J. D., Tyler, G. L., and Flasar, F. H., "Initial Results from Radio Occultation Measurements with Mars Global Surveyor", Journal of Geophysical Research (Planets), 104(E11), 26,297-27,012, 1999.

Justus, C. G., Duvall, A. L. and Johnson, D. L., "Mars Global Reference Atmospheric Model (Mars-GRAM) and Database for Mission Design", in "Mars Atmosphere Modelling and Observations", CNES/ESA 11-5, 2003.

Justus, C. G., Duvall, A. L., and Johnson, D. L., "Mars-GRAM Validation with Mars Global Surveyor Data", Advances in Space Research, 34, 1673-1676, 2004.

Justus, C. G., Duvall, A. L., and Keller, V. W., "Engineering-level Model Atmospheres for Titan and Mars", International Workshop on Planetary Probe Atmospheric Entry and Descent Trajectory Analysis and Science, Lisbon, Portugal, October 6-9, 2003, Proceedings: ESA SP-544, February, 2004.

Justus, C. G., Duvall, A. L., and Keller, V. W., "Atmospheric Models for Aerocapture", AIAA-2004-3844, 40th AIAA/ASME/SAE/ASEE Joint Propulsion Conference, Fort Lauderdale, Florida, July 11-14, 2004.

Justus, C. G., Duvall, A. L., and Keller, V. W., "Validation of Mars-GRAM and Planned New Features", 35th COSPAR Scientific Assembly, Paris, France, July 18-25, 2004.

Justus, C. G., Duvall, A. L., and Keller, V. W., "Atmospheric Models for Aeroentry and Aeroassist", 2nd International Planetary Probe Workshop, NASA Ames Research Center, August 23-26, 2004.

Murphy, J., private communication, 1/13/2005.

Smith, D. E., and Zuber, M. T., "The Relationship between MOLA Northern Hemisphere Topography and the 6.1-mbar Atmospheric Pressure Surface of Mars", Geophysical Research Letters, 25, 4397-4400, 1998.

Smith, M. D., Pearl, J. C., Conrath, B. J., and Christensen, P. R., "One Martian Year of Atmospheric Observations by the Thermal Emission Spectrometer", Geophysical Research Letters, 28(22), 4263-4266, 2001. 
Smith, M. D., "Interannual Variability in TES Atmospheric Observations of Mars during 1999-2003", Icarus, 167, 148-165, 2004. 